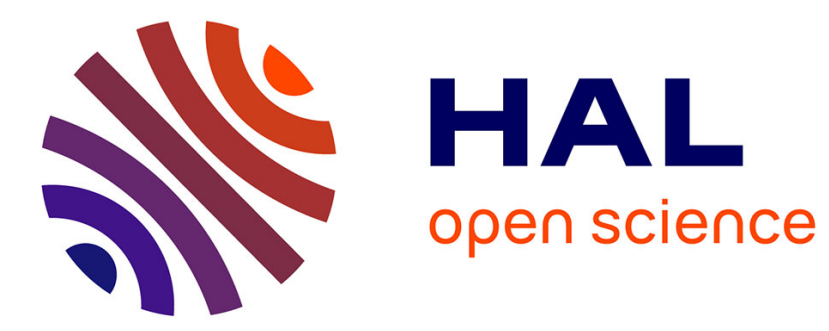

\title{
Adherence to a Mediterranean diet and risk of fractures in French older persons.
}

Catherine Feart, Simon Lorrain, Vanessa Ginder Coupez, Cécilia Samieri, Luc

Letenneur, Damien Paineau, Pascale Barberger-Gateau

\section{- To cite this version:}

Catherine Feart, Simon Lorrain, Vanessa Ginder Coupez, Cécilia Samieri, Luc Letenneur, et al.. Adherence to a Mediterranean diet and risk of fractures in French older persons.. Osteoporosis International, 2013, 24 (12), pp.3031-41. 10.1007/s00198-013-2421-7 . inserm-00850189

\section{HAL Id: inserm-00850189 https://www.hal.inserm.fr/inserm-00850189}

Submitted on 23 Jun 2014

HAL is a multi-disciplinary open access archive for the deposit and dissemination of scientific research documents, whether they are published or not. The documents may come from teaching and research institutions in France or abroad, or from public or private research centers.
L'archive ouverte pluridisciplinaire HAL, est destinée au dépôt et à la diffusion de documents scientifiques de niveau recherche, publiés ou non, émanant des établissements d'enseignement et de recherche français ou étrangers, des laboratoires publics ou privés. 


\section{TITLE PAGE}

Title

Adherence to a Mediterranean diet and risk of fractures in French older persons

\section{Authors}

Catherine FEART ${ }^{1,2}$, Simon LORRAIN ${ }^{1,2}$, Vanessa GINDER COUPEZ ${ }^{3}$, Cécilia SAMIERI ${ }^{1,2}$, Luc $^{2}$ LETENNEUR $^{1,2}$, Damien PAINEAU ${ }^{3}$, Pascale BARBERGER-GATEAU ${ }^{1,2}$

\section{Author Affiliations:}

1. Univ. Bordeaux, ISPED, Centre INSERM U897-Epidemiologie-Biostatistique, F-33000 Bordeaux, France

2. INSERM, ISPED, Centre INSERM U897-Epidemiologie-Biostatistique, F-33000 Bordeaux, France

3. Danone Research, Centre Daniel Carasso, Global Nutrition Department, F-91767 Palaiseau Cedex, France

\section{Corresponding author:}

Catherine FEART

Address: Equipe Epidémiologie de la nutrition et des comportements alimentaires, INSERM, U897, Université Bordeaux Ségalen, ISPED case 11, 146 rue Léo-Saignat, F-33076 BORDEAUX Cedex France

Phone: (33) 547304 204; Fax: (33) 557571486

E-mail: Catherine.Feart@isped.u-bordeaux2.fr

KEY WORDS: Mediterranean diet, fracture, aging

Abstract word count: 250

Text word count: 4,417

Number of tables: 5 
Revised version OI-2013-01-0032, Féart et al.

Number of references: 44

\section{Summary}

Prevention of fractures is a considerable public health challenge. In a population-based cohort of French elderly people, a diet closer to a Mediterranean-type had a borderline significant deleterious effect on the risk of fractures, in part linked to a low consumption of dairy products and a high consumption of fruits. 


\section{ABSTRACT}

3 Purpose: Higher adherence to the Mediterranean diet (MeDi) is linked to a lower risk of several

4 chronic diseases, but its association with the risk of fractures is unclear. Our aim was to investigate the 5 association between MeDi adherence and the risk of fractures in older persons.

6 Methods: The sample consisted of 1,482 individuals aged 67yrs + , from Bordeaux, France, included 7 in the Three-City Study in 2001-2002. Occurrences of hip, vertebral and wrist fractures were self-

8 reported every two years over 8 years and 155 incident fractures were recorded. Adherence to the

9 MeDi was evaluated at baseline by a MeDi score, on a 10-point scale based on a food frequency

10 questionnaire and a 24h recall. Multivariate Cox regression were performed to estimate risk of

11 fractures according to MeDi adherence.

12 Results: Higher MeDi adherence was associated with a non-significant increased risk of fractures at 13 any site (HR per 1-point increase of MeDi score=1.10, $\mathrm{P}=0.08)$ in fully adjusted model. Among MeDi

14 components, higher fruits consumption (>2 servings/day) was significantly associated with an 15 increased risk of hip fractures $(\mathrm{HR}=1.95, \mathrm{P}=0.04)$, while low intake of dairy products was associated 16 with a doubled risk of wrist fractures $(\mathrm{HR}=2.03, \mathrm{P}=0.007)$. An inverse $\mathrm{U}$-shaped association between 17 alcohol intake and risk of total fracture was observed (HR high $v s$ moderate $=0.61, \mathrm{P}$ for trend 0.03 ).

18 Conclusions: Greater MeDi adherence was not associated with a decreased risk of fractures in French 19 older persons. The widely recognized beneficial effects of the MeDi do not seem to apply to bone 20 health in these people. 


\section{INTRODUCTION}

Osteoporosis and osteoporotic fractures, the hallmarks of a long-term initiated process, are responsible for a considerable public health challenge since they are associated with an increased risk of disability, morbidity and mortality with a major economical impact [1-2]. The prevalence of fractures among the elderly persons is estimated at 9 million worldwide, amongst which more than one third are European [3-4]. Therefore, effective strategies to prevent osteoporosis and related fractures must be developed.

The prevention of fractures by modifiable factors including falls prevention and lifestyle, such as physical activity and nutrition, has been well documented in older persons [5-6]. Among dietary factors, much attention has been focused on the beneficial effects of calcium and vitamin D on bone metabolism [7-8]. The role of macronutrients (mainly proteins) and other vitamins (A, B, C, E and K) has also been examined, although their ability to reduce the risk of fractures remains controversial [9].

One explanation of these discordant results could rely on potential additive, synergistic or antagonist effects between components of the diet which are ignored by studies based on single nutrient [10]. Thus, considering comprehensive dietary patterns is an appealing approach [11]. as potential protective factors against development and progression of several age-related diseases [1213]. A limited number of cross-sectional studies have examined the relationship between MeDi adherence and bone health, and they have reported conflicting results. On the one hand, adherence to a traditional MeDi has been associated with higher bone mineral density (BMD) among 100 Spanish postmenopausal women (54 years on average) [14] whereas on the other hand, among 196 Greek women (48 years on average), Kontogianni et al. [15] failed to evidence any association between adherence to the MeDi and indices of bone mass. To our knowledge, the potential protective effect of the MeDi against the risk of hip fractures has been evaluated prospectively only once, in the European Prospective Investigation into Cancer and Nutrition (EPIC) study [16]. In this large cohort of adults $(\mathrm{N}=188,795,49$ years on average and followed for a median of 9 years), a greater MeDi adherence 
49 risk of hip fractures, although the risk factors of fractures are site specific [17]. Moreover, the authors

50 were restrained to develop a modified MeDi score, to better take into account the low consumption of

51 olive oil in non-Mediterranean populations [16].

52 The aim of the present study was to investigate prospectively the relationship between adherence to a

53 MeDi and risk of fractures of the hip, wrist or vertebrae over 8 years, in a large population-based

54 sample of older community-dwellers of both genders living in south-western France. 
SUBJECTS AND METHODS

\section{Participants}

The data came from the Three-City (3C) study, a prospective cohort study of vascular risk factors of dementia whose methodology has been described elsewhere [18]. The 3C study protocol was approved by the Consultative Committee for the Protection of Persons participating in Biomedical Research at

60 Kremlin-Bicêtre University Hospital (Paris). A sample of 9,294 community dwellers aged 65+ was selected in 1999-2000 from the electoral rolls of three French cities (Bordeaux, Dijon and socio-demographic information, lifestyle, symptoms and complaints, medical history, blood pressure, anthropometric data, neuropsychological testing, and blood sampling. Four follow-up examinations were performed, two (wave 1, in 2001-2002), four (wave 2, in 2003-2004), seven (wave 3, in 20062007) and ten years (wave 4, in 2009-2010) after baseline examination. The present study extends between the wave 1 (baseline of this study) and wave 4 in Bordeaux, the only centre where the standard data collection was completed with a comprehensive dietary survey at wave 1 . completed the dietary survey. We first excluded 62 participants who had two missing data or more among dietary items and subsequently excluded 230 participants who were never visited between wave 1 and wave 4 or who never completed history of fractures at visits; leaving 1,482 individuals for the present analyses.

\section{Fractures}

Occurrence of new fractures since the previous examination was self-reported at each visit, as previously described [19]. Hip, vertebrae, wrist, upper member (shoulder, collarbone) and lower member (excluding hip) fractures were recorded. The outcome of interest was incidence of a fracture since wave 1. Because the risk factors of fractures are specific to the site of fracture [17], we studied separately the three main sites of osteoporosis-related fractures: hip fractures, wrist fractures and vertebral fractures. We also created a composite endpoint defined as incidence of a fracture whatever the type among the three sites: hip or wrist or vertebrae. 
Dietary assessment and MeDi score

Participants were visited at home by a trained dietician who administered a food frequency questionnaire (FFQ), not semi-quantitative, and a $24 \mathrm{H}$ dietary recall at wave 1 [20-21]. The $24 \mathrm{H}$ recall was used to estimate nutrient intake in $\mathrm{g} / \mathrm{d}$, total energy intake in $\mathrm{kcal} / \mathrm{d}$ and to compute the ratio of monounsaturated to saturated fat (MUFA-to-SFA). Based on the FFQ, frequency of consumption of 40 categories of foods and beverages for each of the 3 main meals and 3 between-meals snacks was recorded in 11 classes (from never to every days). The food items were aggregated into 20 food and beverage groups as described elsewhere [21]. We identified the food groups considered to be part of the MeDi: vegetables, fruits, legumes, cereals including bread, pasta and rice (whole and refined grains), fish and seafood, meat, dairy products including yoghurts, milk and cheese, and alcohol. Intake of each food group was determined in servings/week. Adherence to the traditional Mediterranean-type diet was assessed by the MeDi score, a 10-point Mediterranean-diet scale. The MeDi score was computed as follows: a value of 0 or 1 was assigned to each food group using sexspecific medians of the population as cut-offs, as suggested earlier by Trichopoulou et al. [22]. For presumed beneficial components for health (ie vegetables, fruits, legumes, cereals and fish), individuals whose consumption was above the median were assigned a value of 1 , vs 0 for the others. For components presumed to be detrimental for health (ie meat and dairy products), individuals whose consumption was below the median were assigned 1, vs. 0 for the others. For alcohol, 1 point was assigned to men if their consumption was within 7-to-14 glasses/week (10-to-20g/d) and to women if their consumption was within 1-to-4 glasses/week (1.4-to-5.7g/d). These cut-offs, corresponding to the second quartile of distribution of total alcohol intake in this population, were chosen to represent mildto-moderate consumption. Finally, participants with a MUFA-to-SFA ratio above the sex-specific median were assigned a value of 1 , vs. 0 for those below the median. The MeDi score was generated by adding the scores ( 0 or 1$)$ for each food category. Thus, the MeDi score could range from 0 to 9 for each participant, with higher scores indicating greater adherence [22].

\section{Covariates}


111 Socio-demographic information recorded at baseline included age, gender and education (six

112 educational levels grouped into four classes: no education or primary school only, secondary (middle)

113 school, high school or vocational school and university). Socio-demographic characteristics also

114 included marital status (married, divorced or separated, widowed, single) and income in four

115 categories (< 750 euros, 750 to 1500 euros, 1500 to 2250 euros, $>2250$ euros per month). Height (in

$116 \mathrm{~m}$ ) and weight (in $\mathrm{kg}$ ) were measured by the interviewers at wave 1 . BMI was computed as the

117 weight $/$ height ${ }^{2}$ ratio and considered in four categories $\left(<21 \mathrm{~kg} / \mathrm{m}^{2}, 21\right.$ to $25 \mathrm{~kg} / \mathrm{m}^{2}, 25$ to $30 \mathrm{~kg} / \mathrm{m}^{2}$, >

$11830 \mathrm{~kg} / \mathrm{m}^{2}$ ). Diabetes was defined as self-reported or as having an anti-diabetic medication at wave 1.

119 Smoking status (never, ex-smoker or current smoker) and regular practice of physical activity (ie

120 doing sport regularly or having at least 1 hour of leisure or household activity per day) were also

121 recorded. Self-reported history of osteoporosis was recorded at each wave. All drugs consumed at least

122 once a week during the last month were collected and prevention or treatment for osteoporosis was

123 recorded, including biphosphonates, raloxifene, strontium ranelate, teriparitide, calcitonine, and

124 supplementation with calcium and/or vitamin D. Long-term corticotherapy was defined as declaring

125 systemic or inhalation corticoid use at both baseline of the 3C study and at wave 1.

\section{Statistical analyses}

128 In a previous report on the same study sample $(\mathrm{N}=1,482)$, baseline demographic and clinical

129 characteristics have been compared between individuals who reported an incident fracture $(n=155)$ and

130 those who remained free from fracture during follow-up [19]. In the present study, we also described

131 the demographic, clinical and dietary characteristics of individuals who reported an incident fracture

132 of the hip, the wrist or the vertebrae separately.

133 The frequency of consumption of each food group composing the MeDi score, expressed as mean

134 number of servings/week, was compared between men and women by Student's t test.

135 We then explored associations between MeDi score and incidence of fractures using Cox

136 proportional hazards models taking age as the time scale. Hazard ratios (HR) and 95\% confidence

137 intervals $(95 \% \mathrm{CI})$ were estimated for 1-point increase of the MeDi score considered as a continuous

138 variable. 
139 These analyses were also performed for each individual MeDi component, adjusted for all other

140 components. For these analyses, MeDi components were considered dichotomously, as defined for the

141 computation of the MeDi score, and a three-level variable was generated to better describe the

142 consumption of alcohol. Indeed, a mild-to-moderate consumption of alcohol, corresponding to the

143 second quartile of distribution of total alcohol intake, was defined by a consumption within 7-to-14

144 glasses/week for men, and within 1-to-4 glasses/week for women and chosen as reference. The first

145 quartile of distribution of total alcohol intake ( $<7$ or 4 glasses/week for men and women respectively)

146 was therefore defined as "no or low consumption", whereas a "high consumption" corresponded to the

147 third and fourth quartiles of distribution (>14 or 4 glasses/week for men and women respectively).

148 Since dairy products constitute a MeDi component of primary interest for bone health, additional

149 Cox proportional hazards analyses were performed considering yoghurts, milk and cheese

150 consumption as individual food categories (1 was assigned to each individual whose consumption of

151 milk, yoghurts or cheese was lower than the respective sex-specific medians of consumption of the

152 sample, otherwise 0). These models were also adjusted for all other dietary components.

153 Covariates were selected for multivariate models when associated with either incidence of hip or

154 wrist or vertebral fracture at a statistical level $\alpha<0.20$ in univariate analyses, as described elsewhere

155 [19]. Two models were performed. First, we adjusted for age, gender, physical activity and total

156 energy intake (model 1). Then, we considered additional adjustment for educational level, marital

157 status, BMI, self-reported osteoporosis, osteoporosis treatment, and intake of calcium and/or vitamin

158 D supplements (model 2).

159 All statistical analyses were performed with SAS Statistical package (Version 9.1 SAS Institute). 


\section{RESULTS}

161 At baseline, the mean age of the participants ( $\mathrm{N}=1,482,550$ men, 932 women) was $75.9 \mathrm{y}$ (range

162 67.7-94.9). Over the 8-y follow-up, 155 individuals reported a fracture at any of the three sites,

163 including 57 hip fractures (46 among women), 43 vertebral fractures ( 37 among women) and 73 wrist

164 fractures (65 among women). Among men (N=550), $23(4.2 \%)$ incident fractures were reported over 8

165 years: $11(2.0 \%)$ hip fractures, $8(1.5 \%)$ wrist fractures and $6(1.1 \%)$ vertebral fractures. Among 932

166 women of the study sample, 132 (14.1\%) incident fractures were reported over 8 years, divided as 46

167 (4.9\%) of hip fractures, 65 (7.0\%) wrist fractures and 37 (4.0\%) vertebral fractures. The

168 sociodemographic and health characteristics of all participants are described in Table 1. Regarding

169 MeDi adherence, individuals with an incident fracture at any of the three sites had a higher mean

170 MeDi score at baseline than those who remained free of fracture during follow-up (4.64, (standard

171 deviation (sd) 1.72) vs. 4.35 (sd 1.67), $\mathrm{P}=0.04)$.

172

173 The sex-specific medians of consumption of food groups used to compute the MeDi score are

174 presented in Table 2. Mean consumption of cheese, meat, legumes and alcohol was significantly lower

175 in women, while mean consumption of yoghurts was significantly higher in women than in men. Mean

176 consumption of vegetables, fruits, fish, milk and of the MUFA-to-SFA ratio was not significantly

177 different between both genders (Table 2).

178

179 In multivariate analyses adjusted for age, gender, physical activity, total energy intake, educational

180 level, marital status, BMI, self-reported osteoporosis, osteoporosis treatment, calcium and/or vitamin

181 D treatment, a borderline significant association between MeDi score and an increased risk of

182 fracture at any site $(\mathrm{HR}=1.10,95 \%$ CI $0.99-1.21, \mathrm{P}=0.08)$, and, specifically of hip fracture $(\mathrm{HR}=$

$1831.18,95 \%$ CI 0.99-1.39, P=0.06) was observed (Table 3, model 2). Conversely, adherence to the

184 MeDi was not significantly associated with the risk of vertebral or wrist fracture.

186 In secondary analyses, we examined whether associations between MeDi adherence and risk of

187 fractures were driven by particular food categories (Table 4). In fully adjusted models, greater fruit 
188 consumption (i.e. >14 servings/week in men and women combined) was significantly associated with

189 a doubled 8-y risk of hip fracture (HR high $v s$ low $=1.95,95 \%$ CI 1.04-3.66, $\mathrm{P}=0.04$ ). Furthermore,

190 lower intake of dairy products (i.e. $<17.0$ servings/week in men and < 17.9 servings/week in women)

191 was significantly associated with an increased risk of fracture at any site (HR low $v s$ high $=1.51,95 \%$

192 CI 1.07-2.11, $\mathrm{P}=0.02$ ), and, specifically, with a doubled risk of wrist fracture (HR low $v s$ high $=2.03$,

193 95\% CI 1.22-3.39, P=0.007), but not other sites. Higher levels of alcohol intake (>14 glasses/week in

194 men and $>4$ glasses/week in women) and marginally, low alcohol intake were associated with a

195 significant reduction (39\% for high intake, $33 \%$ for low intake, $\mathrm{P}$ for trend $=0.03$ ) of risk of fracture at

196 any site. A MUFA-to-SFA ratio higher than 0.8 was significantly associated with a reduced risk of

197 vertebral fracture in the model adjusted for age, gender, physical activity, total energy intake and all

198 other dietary components the MeDi score. However, this association was no longer significant in fully

199 adjusted models.

201 We further analyzed the association between the type of dairy product and the risk of fracture (Table

202 5). Elderly subjects who declared a consumption of yoghurts lower than the median, i.e. $<6$

203 servings/week in men and $<7$ in women, were at increased risk of wrist fracture only (HR low $v s$ high

$204=1.98,95 \%$ CI 1.22-3.21, P=0.005). By contrast, a low consumption of milk or cheese was not

205 associated with the risk of fracture of the hip, the wrist or the vertebrae, in fully adjusted models

206 (Table 5). When considering the risk of fracture whatever the type among the three sites, the low

207 consumption of yoghurts, milk or cheese was not associated with the overall risk of fracture. 
210 In this longitudinal population-based study of French older adults, a greater adherence to a

211 Mediterranean-type diet was significantly associated with an increased risk of fracture, after

212 adjustment for age, gender, physical activity and total energy intake. Two MeDi components appeared 213 to independently drive this association: a high consumption of fruits ( $>2$ servings/day) and a low

214 consumption of yoghurts ( $<1$ serving/day) were significantly associated with a doubled risk of fracture 215 of the hip and the wrist respectively, in fully adjusted models. Moreover, a consumption of alcohol 216 higher than 14 glasses/week for men or 4 glasses/week for women was significantly associated with a $39 \%$ reduced risk of fracture at any site over time.

To our knowledge, a single study reported an inverse association between adherence to a

Mediterranean-type diet and the risk of hip fracture in European older persons [16], which was not in agreement with the present results. Indeed, in this large cohort of adults enrolled in the EPIC study ( $\mathrm{N}=188,795$ participants, 802 incident hip fractures), higher adherence to the MeDi was associated with a 7\% decrease in hip fracture incidence, notably among participants aged 60y + and among men in the model adjusted only for age [16]. In analyses where the dietary components of the MeDi were mutually adjusted, as in the present study, the components that were significantly associated with the risk of hip fracture in the overall sample were vegetables, meat and ethanol intake. However, several differences between the EPIC study and the present one could explain such discrepancies. First,the statistical power of this French study (only 57 incident hip fractures in the present study) was greatly lower than that of the European study. This may have reduce our chance to evidence stronger or additional associations between MeDi adherence and risk of fracture at any site (or at specific site) among French people. Second, the results from the EPIC study suggested that the prevention of hip 232 fracture might be more challenging in women than in men. Only 11 men (among 57) were identified 233 with an incident hip fracture in the present study which prevented us to stratify our analyses based on 234 gender. Third, country specific characteristics of the dietary patterns may partly explain the 235 discrepancies between the French and the EPIC studies. Indeed, a modified MeDi score has been 
defined in the EPIC cohort, by substituting the monounsaturated lipids (MUFA) with the sum of

237 mono- and poly- unsaturated fatty acids in the numerator of the lipid ratio, to better take into account

238 the low consumption of olive oil and MUFA in non-Mediterranean populations [16]. Among the eight

239 countries participating in the EPIC study, only three have Mediterranean origins (Greece, Italy and

240 Spain) but there were no data from France. Traditionally, even among Mediterranean countries,

241 distinct dietary habits exist, as already described by Sofi [23]. More importantly, the MeDi score was

242 computed according to sex-specific medians of consumption of only 9 food groups of each study

243 sample, which limited the generalization of the results and prevented definite conclusions. Altogether,

244 these differences could in part explain the lack of homogeneous results of the association between a

245 Mediterranean-type diet and risk of hip fracture among European and French elderly. Finally,

246 adherence to the MeDi may be considered as lifestyle and may reflect specific health concerns and

247 behaviors that may differ between countries, particularly regarding practice of physical exercise or use

248 of supplements, part of lifestyle but not considered in the diet score computation.

249 Besides, the impact of MeDi adherence on bone health remains unclear. Indeed, of the existing

250 literature, only two cross-sectional studies, including small samples of women, younger than the

251 participants of the present study, were available and yielded mixed results [14-15]. Moreover, a cross-

252 sectional study using another diet quality assessment tool failed to report any significant relation

253 between the Healthy Eating Index (HEI-2005) and several bone turnover markers among post-

254 menopausal women aged $45 y+[24]$.

256 A posteriori derived dietary patterns, independent of any assumption on the beneficial or harmful

257 effects of food intakes, have also been examined in association with bone health, but less often with

258 fracture risk. For instance, a pattern characterized by a high consumption of fruits, vegetables and

259 whole grains might be an optimal dietary strategy to avoid fractures, particularly in older women, in a

260 Canadian study [25]. However, among Japanese adult women, a pattern characterized by high

261 consumption of vegetables was associated with an increased risk of fractures, and another one

262 characterized by a high consumption of meat was associated with a reduced risk of fractures [26].

263 Finally, in the 3C study, we previously reported that dietary patterns rich in cheese, milk and 
charcuteries derived from principal component analysis, were related to a lower risk of hip and wrist fractures over 8-y of follow-up [19].

Among the food groups composing the MeDi score, and unlike most previous studies, we identified an increased risk of hip fractures in participants with a high consumption of fruits, in the fully adjusted model. The association between fruit intake and risk of fractures has scarcely been assessed independently of that of vegetables, which were not associated with the risk of fractures in the present study [27]. A higher fruit consumption was not associated with a significant reduced risk of hip fractures, in the overall sample, in analyses mutually adjusted for the food groups composing the MeDi score in different reports from the EPIC cohort [16][28], suggesting that the relationship between fruit intake and risk of hip fracture remains questionable. The potential benefit of fruits and vegetables is based on their ability to emphasize alkaline status, therefore counterbalancing the acidic load that might lead to osteoporosis [27, 29]; however, conflicting results have also been reported [30].

277 A meta-analysis, which has called the dietary acid-ash hypothesis on bone loss into question,

278 concluded that there is no evidence that an alkaline diet is protective of bone health [29]. Given the 279 lack of biological plausibility for an adverse effect of fruits on bone health, another explanation might 280 be that older adults consuming high amounts of fruits have specific behaviours or health conditions associated with an increased risk of hip fracture, acting as confounding factors that cannot be totally ruled out here despite multivariate adjustment. Finally, we cannot exclude that our unexpected result may be due to chance finding.

As expected, we found that a low consumption of dairy products was significantly associated with an increased risk of fractures. Less attention has been paid in the literature to specific categories of dairy products. In our study, consuming less than one serving of yoghurt/day was associated with a doubled risk of wrist fracture. Dairy products are the main dietary providers of calcium. In a previous paper, we reported that higher MeDi adherents of the $3 \mathrm{C}$ study are those with the lowest calcium intake [31]. Calcium homeostasis and vitamin D status are closely related, particularly with respect to fracture risk

291 [7], although the impact of calcium and/or vitamin D supplementation on the prevention of fracture 
risk remains questionable [32-33]. Regarding milk consumption, our results are in agreement with

those of two meta-analyses in which a low intake of milk was not associated with any marked increase in fracture risk, notably hip fracture risk [34-35].

Alcoholism is known to have negative effects on bone [16, 36], but an inverse U-shaped association between alcohol intake and risk of fracture at any site was observed in the present study. Conversely, a J-shaped relationship between alcohol consumption and hip fracture risk has already been reported [37] and a threshold effect ( 2 units per day or more) has been defined [38]. . Several explanations for these results could be evoked. A first interpretation would be the relevance of using non-drinkers as a reference group, unlike in the current study. Indeed, present non-drinkers may have given up alcohol for medical reasons and be in poorer health status than drinkers. A second interpretation would be that adjustment for major potential confounders was missing in most studies of the existing literature [37], while our models are fully adjusted, including other food groups composing the MeDi score and energy intake. Finally, high alcohol consumers of the current study, identified as men with a consumption $>2$ glasses/day and women with a consumption $>4$ glasses/week, should not be considered as excessive drinkers but as ordinary elderly consumers with French cultural lifestyles including regular alcohol drinking [20].

309 Among the other food groups composing the MeDi score, we did not observe any association with 310 the risk of fractures, whereas some relationships could have been expected. For instance, fish intake,

311 as main provider of dietary vitamin $\mathrm{D}$, has been suggested to be protective against bone loss if

312 consumption was at or over 3 servings/week, while some opposite results exist as well [39-40], and we 313 previously reported that high MeDi adherents of the $3 \mathrm{C}$ study had a mean consumption of 3.7 servings 314 of fish a week [41]. Although still debated, many epidemiological studies, but not the EPIC study, have suggested a positive impact of diets rich in proteins on bone health, especially on the risk of

316 fracture [16, 42-43].

318 There are nevertheless some potential limitations to our findings. First, the FFQ used in the present 319 study did not allow estimation of portion sizes. The lack of estimation of portion size may lead to 
consider people with the same frequency of intake of each food group of the MeDi score as comparable, although they may have different quantitative food consumptions [31, 44]. Regarding outcomes, the self-reported history of fractures could induce an information bias which cannot be checked against objective measures of osteoporosis in this cohort. This could be a major issue especially for vertebral fractures which are initially asymptomatic and thus escape to personal and clinical detection. The lack of association between MeDi adherence, or a component of the MeDi score, with vertebral fractures in fully adjusted models could be in part attributed to their underdiagnosis. Third, a selection bias cannot be dismissed and could have limited our ability to find additional or stronger associations. Not included individuals $(\mathrm{n}=230)$ were significantly older, with lower BMI, were more often sedentary, and had less often diabetes (data not shown). They took less often calcium and/or vitamin D supplements, and had less often treatment for osteoporosis and longterm corticotherapy. Moreover, not included individuals had a lower mean MeDi score than included participants (4.1 (sd 1.5) vs. 4.4 (sd 1.7), $\mathrm{P}=0.02)$. However, the frequency of reported events among participants included in the present study was slightly lower than that expected among European older people [4].

Despite these limitations, the strengths of the present study are the population-based design, including both genders, with long follow-up, the respective account of hip, wrist and vertebrae fracture risk, and the accuracy of food-intake assessment [31]. Moreover, we controlled our analyses for numerous potential confounders including energy intake, BMI, and physical activity. There is a very few vitamin D fortification in most food groups in France, and the calcium and/or vitamin D supplementation and the osteoporosis treatment were also considered as confounders, since they could influence bone health, unlike in the EPIC study.

In conclusion, we found in this large cohort of French elderly community dwellers that a diet closer to a Mediterranean-type diet had a borderline significant deleterious effect on the risk of fractures, in part linked to a low consumption of dairy products and a high consumption of fruits, for which the explanation remains unclear. A high adherence to this French MeDi, as assessed by the MeDi score in the current study, seems not to be beneficial to the prevention of fractures and consequently to bone 
Revised version OI-2013-01-0032, Féart et al.

348 health in French elderly adults [16]. The present results suggested that the widely recognized

349 beneficial effects of the MeDi on health could be reviewed, although more studies are needed to 350 disentangle these results. 


\section{ACKNOWLEDGMENTS}

Funding / Support: The Three-City Study is conducted under a partnership agreement between the Institut National de la Santé et de la Recherche Médicale (INSERM), the Institut de Santé Publique et Développement of the Victor Segalen Bordeaux 2 University, and Sanofi-Aventis. The Fondation pour la Recherche Médicale funded the preparation and initiation of the study. The 3C Study is also supported by the Caisse Nationale Maladie des Travailleurs Salariés, Direction Générale de la Santé, Mutuelle Générale de l'Education Nationale, Institut de la Longévité, Regional Governments of Aquitaine and Bourgogne, Fondation de France, and Ministry of Research - INSERM Programme "Cohortes et collections de données biologiques."

This specific analysis within the Three-City Study was funded by a research agreement between the INSERM and Danone Research.

\section{Conflict of interest}

Catherine Féart received fees for conferences from Danone Research. Cécilia Samieri and Simon Lorrain report no conflict of interest. Luc Letenneur receives research support from Danone Research. Vanessa Ginder Coupez and Damien Paineau are members of Danone Research. Pascale BarbergerGateau served on a scientific advisory board for Caisse Nationale pour la Solidarite et l'Autonomie (CNSA); has received funding for travel and speaker honoraria from Lesieur, Bausch \& Lomb, Aprifel, Danone Institute, Canadian Association of Gerontology, and the Jean Mayer Human Nutrition Research Center on Aging, Tufts University; serves on the editorial boards of Disability and Rehabilitation; has received consultancy fees from Vifor Pharma; and receives research support from Lesieur, Danone, Agence Nationale de la Recherche, Conseil Régional d'Aquitaine, Institut Carnot LISA and Groupe Lipides et Nutrition.

\section{Authors' contributions to manuscript}

1) designed research (project conception, development of overall research plan, and study oversight): PBG, DP 
2) conducted research (hands-on conduct of the experiments and data collection): PBG, LL

3) provided essential reagents or provided essential materials: PBG, LL

4) analyzed data or performed statistical analysis: CF, SL

5) wrote paper: CF, PBG

6) had primary responsibility for final content: $\mathrm{CF}$

7) provided significant advice: PBG, LL,VC, CS, DP

All the authors read the draft critically. 


\section{REFERENCES}

1. Burge R, Dawson-Hughes B, Solomon DH, Wong JB, King A, Tosteson A: Incidence and economic burden of osteoporosis-related fractures in the United States, 20052025. J Bone Miner Res 2007, 22(3):465-475.

2. Rachner TD, Khosla S, Hofbauer LC: Osteoporosis: now and the future. Lancet 2011, 377(9773):1276-1287.

3. Johnell O, Kanis JA: An estimate of the worldwide prevalence and disability associated with osteoporotic fractures. Osteoporos Int 2006, 17(12):1726-1733.

4. Kanis JA, Oden A, McCloskey EV, Johansson H, Wahl DA, Cooper C: A systematic review of hip fracture incidence and probability of fracture worldwide. Osteoporos Int 2012, 23(9):2239-2256.

5. Body JJ, Bergmann P, Boonen S, Boutsen Y, Bruyere O, Devogelaer JP, Goemaere S, Hollevoet N, Kaufman JM, Milisen K et al: Non-pharmacological management of osteoporosis: a consensus of the Belgian Bone Club. Osteoporos Int 2011, 22(11):2769-2788.

6. Tucker KL: Osteoporosis prevention and nutrition. Curr Osteoporos Rep 2009, 7(4):111-117.

7. Chung M, Lee J, Terasawa T, Lau J, Trikalinos TA: Vitamin D with or without calcium supplementation for prevention of cancer and fractures: an updated metaanalysis for the U.S. Preventive Services Task Force. Ann Int Med 2011, 155(12):827-838.

8. Bischoff-Ferrari HA, Willett WC, Orav EJ, Lips P, Meunier PJ, Lyons RA, Flicker L, Wark J, Jackson RD, Cauley JA et al: A pooled analysis of vitamin D dose requirements for fracture prevention. $N$ Engl J Med 2012, 367(1):40-49.

9. Ahmadieh H, Arabi A: Vitamins and bone health: beyond calcium and vitamin D. Nutr Rev 2011, 69(10):584-598.

10. Kant AK: Dietary patterns and health outcomes. J Am Diet Assoc 2004, 104(4):615635.

11. Jacobs DR, Jr., Gross MD, Tapsell LC: Food synergy: an operational concept for understanding nutrition. Am J Clin Nutr 2009, 89(5):1543S-1548S.

12. Sofi F, Abbate R, Gensini GF, Casini A: Accruing evidence on benefits of adherence to the Mediterranean diet on health: an updated systematic review and meta-analysis. Am J Clin Nutr 2010, 92(5):1189-1196.

13. Feart C, Samieri C, Barberger-Gateau P: Mediterranean diet and cognitive function in older adults. Curr Opin Clin Nutr Metab Care 2010, 13(1):14-18.

14. Rivas A, Romero A, Mariscal-Arcas M, Monteagudo C, Feriche B, Lorenzo ML, Olea F: Mediterranean diet and bone mineral density in two age groups of women. Int $J$ Food Sci Nutr 2012.

15. Kontogianni MD, Melistas L, Yannakoulia M, Malagaris I, Panagiotakos DB, Yiannakouris N: Association between dietary patterns and indices of bone mass in a sample of Mediterranean women. Nutrition 2009, 25(2):165-171.

16. Benetou V, Orfanos P, Pettersson-Kymmer U, Bergstrom U, Svensson O, Johansson I, Berrino F, Tumino R, Borch KB, Lund E et al: Mediterranean diet and incidence of hip fractures in a European cohort. Osteoporos Int 2012.

17. Cummings SR, Melton LJ: Epidemiology and outcomes of osteoporotic fractures. Lancet 2002, 359(9319):1761-1767.

18. The 3C Study Group: Vascular factors and risk of dementia: design of the Three-City Study and baseline characteristics of the study population. Neuroepidemiol 2003, 22:316-325. 
19. Samieri C, Ginder Coupez V, Lorrain S, Letenneur L, Alles B, Feart C, Paineau D, Barberger-Gateau P: Nutrient patterns and risk of fracture in older subjects: results from the Three-City Study. Osteoporos Int 2012.

20. Feart C, Jutand MA, Larrieu S, Letenneur L, Delcourt C, Combe N, Barberger-Gateau P: Energy, macronutrient and fatty acid intake of French elderly community dwellers and association with socio-demographic characteristics: data from the Bordeaux sample of the Three-City Study. Br J Nutr 2007, 98:1046-1057.

21. Samieri C, Jutand MA, Feart C, Capuron L, Letenneur L, Barberger-Gateau P: Dietary patterns derived by hybrid clustering method in older people: association with cognition, mood, and self-rated health. J Am Diet Assoc 2008, 108(9):1461-1471.

22. Trichopoulou A, Costacou T, Bamia C, Trichopoulos D: Adherence to a Mediterranean diet and survival in a Greek population. N Engl J Med 2003, 348(26):2599-2608.

23. Sofi F: The Mediterranean diet revisited: evidence of its effectiveness grows. Curr Opin Cardiol 2009, 24(5):442-446.

24. Hamidi M, Tarasuk V, Corey P, Cheung AM: Association between the Healthy Eating Index and bone turnover markers in US postmenopausal women aged $>/=45 \mathrm{y} . A m J$ Clin Nutr 2011, 94(1):199-208.

25. Langsetmo L, Hanley DA, Prior JC, Barr SI, Anastassiades T, Towheed T, Goltzman D, Morin S, Poliquin S, Kreiger N: Dietary patterns and incident low-trauma fractures in postmenopausal women and men aged $>/=50 \mathrm{y}$ : a population-based cohort study. Am J Clin Nutr 2011, 93(1):192-199.

26. Monma Y, Niu K, Iwasaki K, Tomita N, Nakaya N, Hozawa A, Kuriyama S, Takayama S, Seki T, Takeda T et al: Dietary patterns associated with fall-related fracture in elderly Japanese: a population based prospective study. BMC Geriatr 2010, $10: 31$.

27. Hamidi M, Boucher BA, Cheung AM, Beyene J, Shah PS: Fruit and vegetable intake and bone health in women aged 45 years and over: a systematic review. Osteoporos Int 2011, 22(6):1681-1693.

28. Benetou V, Orfanos P, Zylis D, Sieri S, Contiero P, Tumino R, Giurdanella MC, Peeters PH, Linseisen J, Nieters A et al: Diet and hip fractures among elderly Europeans in the EPIC cohort. Eur J Clin Nutr 2011, 65(1):132-139.

29. Fenton TR, Tough SC, Lyon AW, Eliasziw M, Hanley DA: Causal assessment of dietary acid load and bone disease: a systematic review \& meta-analysis applying Hill's epidemiologic criteria for causality. Nutr J 2011, 10:41.

30. McLean RR, Qiao N, Broe KE, Tucker KL, Casey V, Cupples LA, Kiel DP, Hannan MT: Dietary acid load is not associated with lower bone mineral density except in older men. J Nutr 2011, 141(4):588-594.

31. Feart C, Alles B, Merle B, Samieri C, Barberger-Gateau P: Adherence to a Mediterranean diet and energy, macro-, and micronutrient intakes in older persons. $J$ Physiol Biochem 2012, 68(4):691-700.

32. Ott SM: Review: Vitamin D with calcium reduces fractures in adults. Ann Int Med 2012, 156(12):JC6-7.

33. Rabenda V, Bruyere O, Reginster JY: Relationship between bone mineral density changes and risk of fractures among patients receiving calcium with or without vitamin D supplementation: a meta-regression. Osteoporos Int 2011, 22(3):893-901.

34. Kanis JA, Johansson H, Oden A, De Laet C, Johnell O, Eisman JA, Mc Closkey E, Mellstrom D, Pols H, Reeve J et al: A meta-analysis of milk intake and fracture risk: low utility for case finding. Osteoporos Int 2005, 16(7):799-804. 
35. Bischoff-Ferrari HA, Dawson-Hughes B, Baron JA, Kanis JA, Orav EJ, Staehelin HB, Kiel DP, Burckhardt P, Henschkowski J, Spiegelman D et al: Milk intake and risk of hip fracture in men and women: a meta-analysis of prospective cohort studies. $J$ Bone Miner Res 2011, 26(4):833-839.

36. Drake MT, Murad MH, Mauck KF, Lane MA, Undavalli C, Elraiyah T, Stuart LM, Prasad C, Shahrour A, Mullan RJ et al: Risk factors for low bone mass-related fractures in men: a systematic review and meta-analysis. J Clin Endocrinol Metab 2012, 97(6):1861-1870.

37. Berg KM, Kunins HV, Jackson JL, Nahvi S, Chaudhry A, Harris KA, Jr., Malik R, Arnsten JH: Association between alcohol consumption and both osteoporotic fracture and bone density. Am J Med 2008, 121(5):406-418.

38. Kanis JA, Johansson H, Johnell O, Oden A, De Laet C, Eisman JA, Pols H, Tenenhouse A: Alcohol intake as a risk factor for fracture. Osteoporos Int 2005, 16(7):737-742.

39. Farina EK, Kiel DP, Roubenoff R, Schaefer EJ, Cupples LA, Tucker KL: Protective effects of fish intake and interactive effects of long-chain polyunsaturated fatty acid intakes on hip bone mineral density in older adults: the Framingham Osteoporosis Study. Am J Clin Nutr 2011, 93(5):1142-1151.

40. Virtanen JK, Mozaffarian D, Cauley JA, Mukamal KJ, Robbins J, Siscovick DS: Fish consumption, bone mineral density, and risk of hip fracture among older adults: the cardiovascular health study. J Bone Miner Res 2010, 25(9):1972-1979.

41. Feart C, Samieri C, Rondeau V, Amieva H, Portet F, Dartigues JF, Scarmeas N, Barberger-Gateau P: Adherence to a Mediterranean diet, cognitive decline, and risk of dementia. Jama 2009, 302(6):638-648.

42. Dargent-Molina P, Sabia S, Touvier M, Kesse E, Breart G, Clavel-Chapelon F, Boutron-Ruault MC: Proteins, dietary acid load, and calcium and risk of postmenopausal fractures in the E3N French women prospective study. J Bone Miner Res 2008, 23(12):1915-1922.

43. Jesudason D, Clifton P: The interaction between dietary protein and bone health. $J$ Bone Miner Metab 2011, 29(1):1-14.

44. Feart C, Samieri C, Alles B, Barberger-Gateau P: Potential benefits of adherence to the Mediterranean diet on cognitive health. Proc Nutr Soc 2013, 72(1):140-152. 
Table 1. Baseline demographic, health and dietary characteristics of the participants at baseline according to 8-year incidence of a fracture, in the Bordeaux sample of the Three-City study (2001-2009) (N=1482)

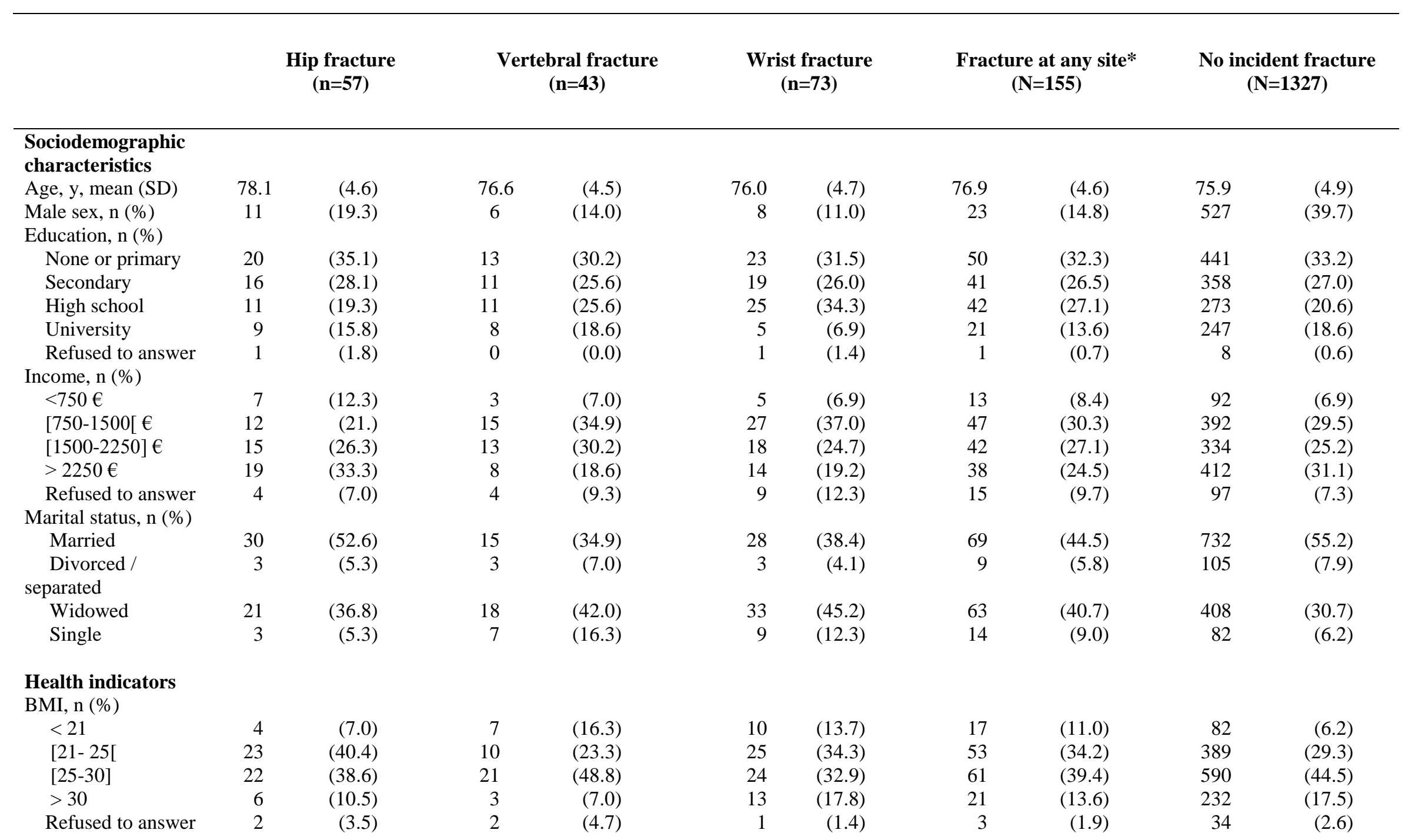




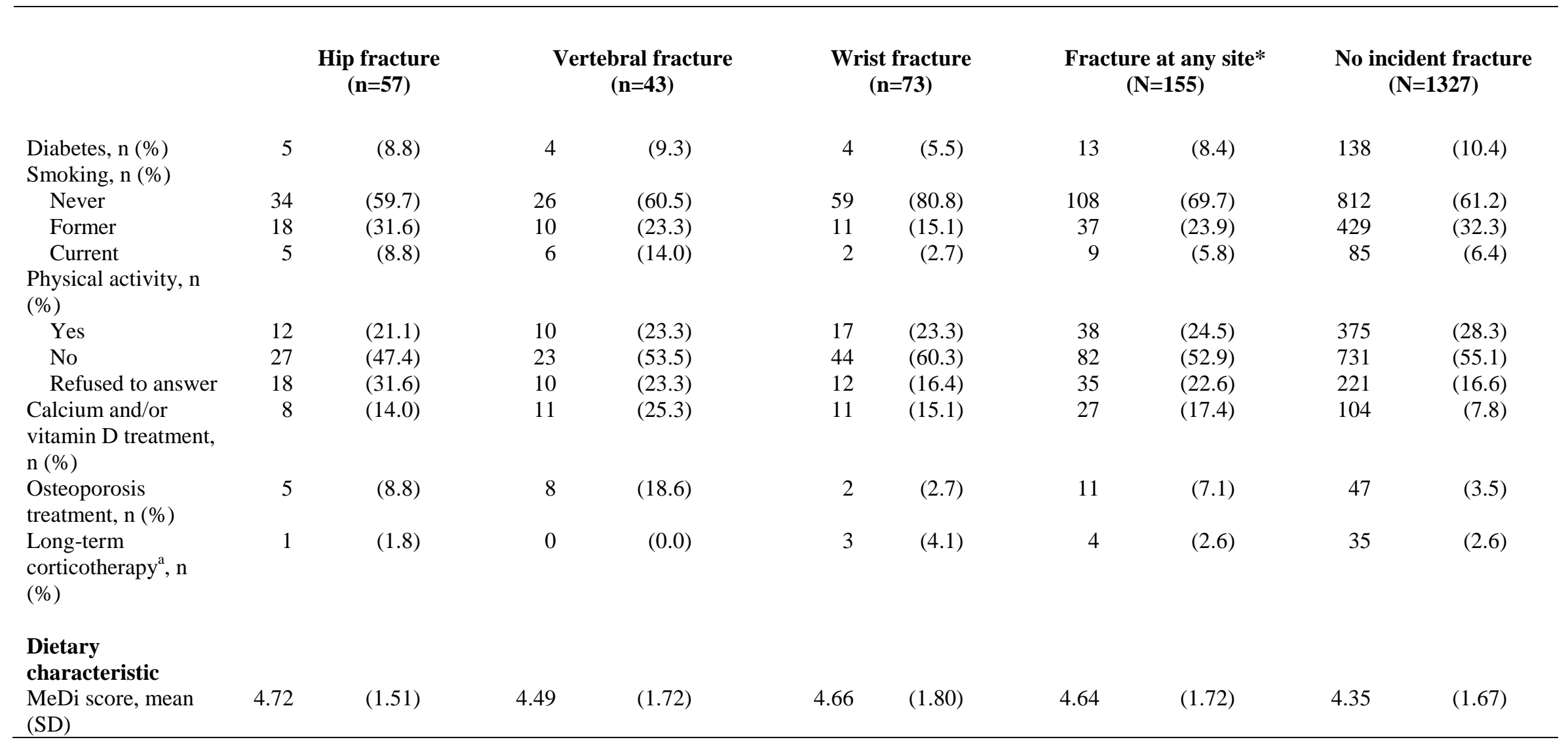

Abbreviations: BMI: Body Mass Index.

${ }^{\text {a }}$ systemic or inhalation corticoid use both at baseline of the $3 \mathrm{C}$ study and at wave 1

* Fracture at any sites among the hip, the wrist and the vertebrae 
Table 2. Baseline median and mean number of servings per week for individual MeDi components and mean MUFA-to-SFA ratio by gender, among older persons living in Bordeaux, The Three-City study (2001-2002) (N=1482)

\begin{tabular}{|c|c|c|c|c|c|c|c|}
\hline & & $\begin{array}{l}\text { Men } \\
n=550\end{array}$ & & & $\begin{array}{l}\text { omen } \\
=932\end{array}$ & & \\
\hline Food categories, servings per week & Median & Mean & $\mathrm{SD}$ & Median & Mean & SD & $\mathrm{P}^{*}$ \\
\hline Dairy products & 17.0 & 18.0 & 7.8 & 17.9 & 18.6 & 7.8 & 0.15 \\
\hline Yoghurt & 6.0 & 5.8 & 4.9 & 7.0 & 8.0 & 5.2 & $<0.0001$ \\
\hline Milk & 0.25 & 3.7 & 4.4 & 0.25 & 3.4 & 4.5 & 0.13 \\
\hline Cheese & 7.0 & 8.4 & 4.7 & 7.0 & 7.2 & 4.5 & $<0.0001$ \\
\hline Meat & 5.0 & 5.3 & 2.6 & 4.0 & 4.5 & 2.3 & $<0.0001$ \\
\hline Vegetables & 19.1 & 19.6 & 7.3 & 18.0 & 19.0 & 7.2 & 0.13 \\
\hline Fruits & 14.0 & 13.2 & 6.7 & 14.0 & 13.7 & 7.0 & 0.17 \\
\hline Legumes & 0.5 & 0.8 & 0.8 & 0.5 & 0.5 & 0.5 & $<0.0001$ \\
\hline Cereals ${ }^{\text {a }}$ & 23.6 & 23.2 & 5.2 & 23.0 & 21.3 & 6.5 & $<0.0001$ \\
\hline Fish & 2.8 & 2.9 & 1.7 & 2.5 & 2.8 & 1.8 & 0.35 \\
\hline MUFA-to-SFA ratio ${ }^{b}$ & 0.8 & 0.9 & 0.3 & 0.8 & 0.9 & 0.3 & 0.99 \\
\hline Alcohol $^{\mathrm{c}}$ & & 16.9 & 14.6 & & 5.9 & 6.8 & $<0.0001$ \\
\hline No or low & & 1.8 & 1.8 & & 0.0 & 0.0 & $<0.0001$ \\
\hline Mild-to-moderate & & 9.7 & 3.0 & & 2.0 & 1.1 & $<0.0001$ \\
\hline High & & 27.9 & 12.9 & & 11.2 & 6.4 & $<0.0001$ \\
\hline
\end{tabular}

Abbreviations: MUFA-to-SFA Monounsaturated fatty acid-to-saturated fatty acid ratio

${ }^{a}$ Cereals included consumption of cereals, bread, pasta and rice (whole and refined grains)

${ }^{\mathrm{b}}$ The $24 \mathrm{H}$ recall was used to compute the MUFA-to-SFA ratio (intake $\mathrm{g} / \mathrm{d}$ )

${ }^{\mathrm{c}}$ Number of glasses per week. For the computation of the MeDi score, we attributed a value of 1 for people whose consumption was mild-to moderate, corresponding to the second quartile of distribution of total alcohol intake. One point was given to men if their consumption was within 7-to-14 glasses per week (10-to-20g/d) $(\mathrm{N}=150)$ and to women if consumption was within 1-to-4 (1.4-to-5.7g/d) glasses per week $(\mathrm{N}=238)$. "No or low consumption" corresponded to the first quartile of distribution of total alcohol intake (less than 7 or 4 glasses per week for men $(\mathrm{N}=126)$ and women $(\mathrm{N}=244)$ respectively). "High consumption" corresponded to the third and fourth quartiles of distribution (over 14 or 4 glasses per week for men $(\mathrm{N}=274)$ and women $(\mathrm{N}=450)$ respectively).

* $P$-value for Student's $t$ test comparing mean consumption of individual food intake or ratios between men and women. 
Table 3. Multivariate associations between adherence to a Mediterranean diet, as assessed by the MeDi Score (continuous) at baseline, and incidence of fracture among older persons living in Bordeaux, The Three-City study (2001-2009)

\begin{tabular}{|c|c|c|c|c|c|c|c|c|}
\hline & \multicolumn{2}{|c|}{ Hip fracture } & \multicolumn{2}{|c|}{ Vertebral fracture } & \multicolumn{2}{|c|}{ Wrist fracture } & \multicolumn{2}{|c|}{ Fracture at any site* } \\
\hline & $\begin{array}{c}\mathrm{HR} \\
(95 \% \mathrm{CI})\end{array}$ & $\mathrm{P}$ & $\begin{array}{c}\mathrm{HR} \\
(95 \% \mathrm{CI})\end{array}$ & $\mathrm{P}$ & $\begin{array}{c}\mathrm{HR} \\
(95 \% \mathrm{CI})\end{array}$ & $\mathrm{P}$ & $\begin{array}{c}\text { HR } \\
(95 \% \mathrm{CI})\end{array}$ & $\mathrm{P}$ \\
\hline Model $1(\mathrm{~N}=1,482)$ & & & & & & & & \\
\hline MeDi Score & $\begin{array}{c}1.18 \\
(1.00-1.39)\end{array}$ & 0.05 & $\begin{array}{c}1.06 \\
(0.88-1.28)\end{array}$ & 0.54 & $\begin{array}{c}1.12 \\
(0.97-1.29)\end{array}$ & 0.13 & $\begin{array}{c}1.12 \\
(1.02-1.24)\end{array}$ & 0.02 \\
\hline Model $2(\mathrm{~N}=1,435)$ & & & & & & & & \\
\hline MeDi Score & $\begin{array}{c}1.18 \\
(0.99-1.39)\end{array}$ & 0.06 & $\begin{array}{c}1.06 \\
(0.87-1.29)\end{array}$ & 0.55 & $\begin{array}{c}1.09 \\
(0.94-1.26)\end{array}$ & 0.25 & $\begin{array}{c}1.10 \\
(0.99-1.21)\end{array}$ & 0.08 \\
\hline
\end{tabular}

Abbreviations: MeDi Mediterranean diet; HR Hazard ratio; CI Confidence Intervals

Hazard ratios (HR) and 95\% confidence intervals (95\% CI) were estimated for 1-unit increase of the MeDi score

$\mathrm{P}$-value for Cox proportional hazard models

* Fracture at any sites among the hip, the wrist and the vertebrae

Model 1 was adjusted for age, gender, physical activity and total energy intake

Model 2 as Model 1 plus additional adjustment for educational level, marital status, BMI, self-reported osteoporosis, osteoporosis treatment, calcium and/or vitamin $\mathrm{D}$ treatment 
Table 4. Multivariate associations between individual food groups component of the Mediterranean diet score at baseline and incidence of fracture among older persons living in Bordeaux, The Three-City study (2001-2009)

\begin{tabular}{|c|c|c|c|c|c|c|c|c|}
\hline & \multicolumn{2}{|c|}{ Hip fracture } & \multicolumn{2}{|c|}{ Vertebral fracture } & \multicolumn{2}{|c|}{ Wrist fracture } & \multicolumn{2}{|c|}{ Fracture at any site* } \\
\hline & $\begin{array}{c}\mathrm{HR} \\
(95 \% \mathrm{CI})\end{array}$ & $\mathrm{P}$ & $\begin{array}{c}\mathrm{HR} \\
(95 \% \mathrm{CI})\end{array}$ & $\mathrm{P}$ & $\begin{array}{c}\mathrm{HR} \\
(95 \% \mathrm{CI})\end{array}$ & $\mathrm{P}$ & $\begin{array}{c}\mathrm{HR} \\
(95 \% \mathrm{CI})\end{array}$ & $\mathrm{P}$ \\
\hline \multicolumn{9}{|l|}{ Model $1(\mathrm{~N}=1,482) \dagger$} \\
\hline Low dairy products & $1.03(0.60-1.76)$ & 0.92 & $1.73(0.91-3.27)$ & 0.09 & $1.97(1.20-3.24)$ & 0.008 & $1.58(1.13-2.20)$ & 0.007 \\
\hline Low meats & $0.96(0.55-1.68)$ & 0.88 & $0.71(0.37-1.39)$ & 0.32 & $0.74(0.44-1.22)$ & 0.23 & $0.78(0.56-1.10)$ & 0.16 \\
\hline High vegetables & $1.51(0.86-2.68)$ & 0.15 & $1.45(0.75-2.77)$ & 0.27 & $0.69(0.43-1.11)$ & 0.12 & $1.01(0.72-1.40)$ & 0.97 \\
\hline High fruits & $1.74(0.96-3.16)$ & 0.07 & $0.75(0.40-1.39)$ & 0.36 & $1.15(0.71-1.85)$ & 0.58 & $1.16(0.83-1.62)$ & 0.38 \\
\hline High legumes & $0.93(0.54-1.59)$ & 0.78 & $1.06(0.56-2.00)$ & 0.85 & $0.93(0.58-1.50)$ & 0.76 & $0.96(0.69-1.33)$ & 0.78 \\
\hline High cereals $^{\mathrm{a}}$ & $1.09(0.62-1.90)$ & 0.77 & $0.95(0.51-1.80)$ & 0.88 & $1.41(0.86-2.31)$ & 0.18 & $1.11(0.79-1.55)$ & 0.56 \\
\hline High fish & $1.07(0.62-1.85)$ & 0.81 & $1.54(0.82-2.91)$ & 0.18 & $1.05(0.65-1.70)$ & 0.83 & $1.33(0.95-1.85)$ & 0.10 \\
\hline High MUFA-to-SFA ratio & $0.98(0.57-1.67)$ & 0.94 & $0.48(0.25-0.91)$ & 0.02 & $1.47(0.90-2.38)$ & 0.12 & $0.94(0.68-1.31)$ & 0.73 \\
\hline \multicolumn{9}{|c|}{ 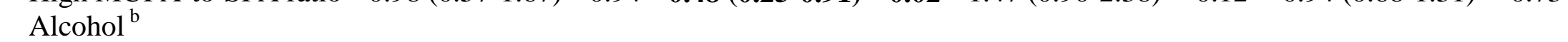 } \\
\hline No or low & $0.48(0.23-1.03)$ & 0.15 & $0.46(0.19-1.13)$ & 0.17 & $0.94(0.52-1.69)$ & 0.13 & $0.66(0.43-1.02)$ & $\mathbf{0 . 0 3}$ \\
\hline Mild-to-moderate & 1 & & 1 & & 1 & & $\mathbf{1}$ & \\
\hline High & $0.69(0.38-1.25)$ & & $0.60(0.31-1.18)$ & & $0.59(0.34-1.03)$ & & $0.63(0.43-0.90)$ & \\
\hline \multicolumn{9}{|l|}{ Model $2(N=1,435) \dagger$} \\
\hline Low dairy products & $0.95(0.54-1.68)$ & 0.86 & $1.53(0.79-2.95)$ & 0.21 & $2.03(1.22-3.39)$ & 0.007 & $1.51(1.07-2.11)$ & 0.02 \\
\hline Low meats & $0.99(0.55-1.78)$ & 0.96 & $0.70(0.35-1.40)$ & 0.31 & $0.62(0.36-1.05)$ & 0.08 & $0.74(0.52-1.06)$ & 0.10 \\
\hline High vegetables & $1.52(0.84-2.74)$ & 0.17 & $1.40(0.70-2.79)$ & 0.34 & $0.70(0.42-1.14)$ & 0.15 & $1.00(0.71-1.41)$ & 0.99 \\
\hline High fruits & $1.95(1.04-3.66)$ & 0.04 & $0.70(0.36-1.36)$ & 0.29 & $1.13(0.69-1.86)$ & 0.63 & $1.15(0.82-1.63)$ & 0.42 \\
\hline High legumes & $0.84(0.47-1.48)$ & 0.54 & $0.92(0.47-1.80)$ & 0.80 & $1.02(0.62-1.70)$ & 0.93 & $0.92(0.65-1.29)$ & 0.62 \\
\hline High cereals ${ }^{\text {a }}$ & $0.98(0.55-1.75)$ & 0.94 & $1.05(0.54-2.06)$ & 0.88 & $1.25(0.76-2.07)$ & 0.39 & $1.04(0.74-1.47)$ & 0.81 \\
\hline High fish & $1.18(0.67-2.09)$ & 0.57 & $1.58(0.81-3.08)$ & 0.18 & $0.98(0.60-1.61)$ & 0.94 & $1.29(0.92-1.81)$ & 0.14 \\
\hline High MUFA-to-SFA ratio & $1.00(0.57-1.75)$ & 0.99 & $0.61(0.31-1.18)$ & 0.14 & $1.40(0.85-2.31)$ & 0.19 & $0.94(0.67-1.31)$ & 0.72 \\
\hline Alcohol $^{\mathrm{b}}$ & & & & & & & & $\mathbf{0 . 0 3}$ \\
\hline No or low & $0.45(0.20-1.00)$ & 0.12 & $0.46(0.18-1.22)$ & 0.24 & $1.01(0.55-1.86)$ & 0.07 & $0.67(0.43-1.05)$ & \\
\hline Mild-to-moderate & 1 & & 1 & & 1 & & 1 & \\
\hline High & $0.64(0.35-1.18)$ & & $0.64(0.32-1.30)$ & & $0.55(0.31-0.98)$ & & $0.61(0.42-0.88)$ & \\
\hline
\end{tabular}


Abbreviations: HR Hazard ratio; CI Confidence Intervals

Hazard ratios (HR) and 95\% confidence intervals (95\% CI) were estimated for 1-unit increase of the MeDi score

$\mathrm{P}$-value for Cox proportional hazard models

* Fracture at any sites among the hip, the wrist and the vertebrae

$\uparrow$ These consumptions corresponded to one point attributed in the computation of the Mediterranean diet score. A low consumption of dairy products corresponded to less than 17.0 servings/week for men and 17.9 for women. A low consumption of meats corresponded to less than 5.0 servings/week for men and 4.0 for women. A high consumption of vegetables corresponded to more than 19.1 servings/week for men and 18.0 for women. A high consumption of fruits corresponded to more than 14.0 servings/week for men and women. A high consumption of legumes corresponded to more than $0.5 \mathrm{serving} /$ week for men and women. A high consumption of cereals corresponded to more than 23.6 servings/week for men and 23.0 for women. A high consumption of fish corresponded to more than 2.8 servings/week for men and 2.5 for women. A high MUFA-to-SFA ratio corresponded to a ratio higher than 0.8 for men and women.

${ }^{a}$ Cereals included consumption of cereals, bread, pasta and rice (whole and refined grains)

${ }^{\mathrm{b}}$ For the computation of the MeDi score, we attributed a value of 1 for people whose consumption was mild-to moderate, corresponding to the second quartile of distribution of total alcohol intake. One point was given to men if their consumption was within 7-to-14 glasses per week and to women if consumption was within 1-to-4 glasses per week. This category was chosen as reference in this analysis. "No or low consumption" corresponded to the first quartile of distribution of total alcohol intake (less than 7 or 4 glasses per week for men and women respectively). "High consumption" corresponded to the third and fourth quartiles of distribution (over 14 or 4 glasses per week for men and women respectively).

Model 1 was adjusted for each individual food group component of the Mediterranean diet score, age, gender, physical activity and total energy intake

Model 2 as Model 1 plus additional adjustment for educational level, marital status, BMI, self-reported osteoporosis, osteoporosis treatment, calcium and/or vitamin D treatment 
Table 5. Multivariate association between dairy products consumption at baseline and incidence of fracture among older persons living in Bordeaux, The Three-City study (2001-2009)

\begin{tabular}{|c|c|c|c|c|c|c|c|c|}
\hline & \multicolumn{2}{|c|}{ Hip fracture } & \multicolumn{2}{|c|}{ Vertebral fracture } & \multicolumn{2}{|c|}{ Wrist fracture } & \multicolumn{2}{|c|}{ Fracture at any site $*$} \\
\hline & $\begin{array}{c}\text { HR } \\
(95 \% \mathrm{CI})\end{array}$ & $\mathbf{P}$ & $\begin{array}{c}\text { HR } \\
(95 \% \mathrm{CI})\end{array}$ & $\mathbf{P}$ & $\begin{array}{c}\text { HR } \\
(95 \% \mathrm{CI})\end{array}$ & $\mathbf{P}$ & $\begin{array}{c}\text { HR } \\
(95 \% \mathrm{CI})\end{array}$ & $\mathbf{P}$ \\
\hline \multicolumn{9}{|c|}{ Model $1(\mathrm{~N}=1,482) \dagger$} \\
\hline Low yoghurts & $1.06(0.61-1.87)$ & 0.82 & $0.87(0.45-1.70)$ & 0.68 & $1.85(1.16-2.94)$ & 0.01 & $1.25(0.90-1.75)$ & 0.18 \\
\hline Low milk & $1.23(0.72-2.10)$ & 0.45 & $1.26(0.68-2.36)$ & 0.46 & $0.99(0.62-1.58)$ & 0.95 & $1.16(0.84-1.60)$ & 0.38 \\
\hline Low cheese & $1.44(0.84-2.49)$ & 0.19 & $1.49(0.80-2.78)$ & 0.21 & $1.08(0.67-1.76)$ & 0.75 & $1.23(0.88-1.71)$ & 0.23 \\
\hline \multicolumn{9}{|c|}{ Model $2(\mathrm{~N}=1.435) \dagger$} \\
\hline Low yoghurts & $1.11(0.62-1.99)$ & 0.72 & $0.85(0.42-1.70)$ & 0.64 & $1.98(1.22-3.21)$ & 0.005 & $1.29(0.92-1.81)$ & 0.15 \\
\hline Low milk & $1.16(0.67-2.02)$ & 0.60 & $1.15(0.60-2.20)$ & 0.68 & $0.96(0.59-1.56)$ & 0.88 & $1.10(0.79-1.53)$ & 0.57 \\
\hline Low cheese & $1.28(0.72-2.28)$ & 0.40 & $1.55(0.80-2.99)$ & 0.19 & $0.98(0.59-1.62)$ & 0.93 & $1.14(0.81-1.61)$ & 0.46 \\
\hline
\end{tabular}

Abbreviations: HR Hazard ratio; CI Confidence Intervals

Hazard ratios (HR) and 95\% confidence intervals (95\% CI) were estimated for 1-unit increase of the MeDi score

* Fracture at any sites among the hip, the wrist and the vertebrae

$\uparrow$ These consumptions corresponded to one point attributed for the considered food group in the computation of the Mediterranean diet score. Participants received 1 point if their intake of yoghurts was lower than 6 servings/week for men and 7 servings/week for women; if their intake of milk was lower than 0.25 serving/week for men and women; and if their intake of cheese was lower than 7 servings/week for men and women.

Model 1 was adjusted for each individual food group component of the Mediterranean diet score, age, gender, physical activity and total energy intake

Model 2 as Model 1 plus additional adjustment for educational level, marital status, BMI, self-reported osteoporosis, osteoporosis treatment, calcium and/or vitamin D treatment 